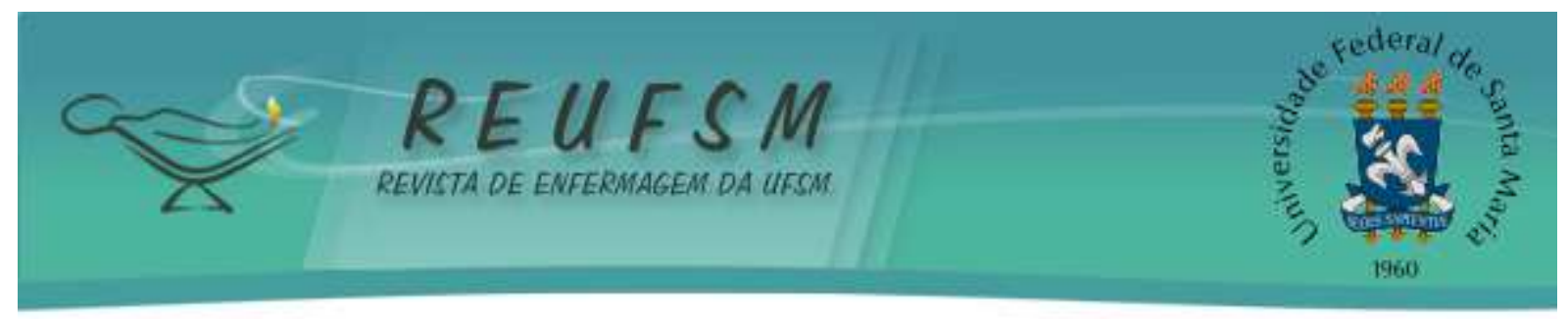

\title{
NOVAS POSSIBILIDADES DA TEORIA FUNDAMENTADA NOS DADOS PARA A PESQUISA EM ENFERMAGEM
}

\section{NEW POSSIBILITIES OF THE GROUNDED THEORY FOR NURSING RESEARCH NUEVAS POSIBILIDADES DE LA TEORÍA FUNDAMENTADA EN LOS DATOS PARA LA INVESTIGACIÓN EN ENFERMERÍA}

José Luís Guedes dos $\operatorname{Santos}^{1}$

Doi: $10.5902 / 2179769231767$

A Teoria Fundamentada nos Dados (TFD), conforme o próprio nome já indica, possibilita o desenvolvimento de teorias a partir de dados empíricos. Ela foi desenvolvida pelos sociólogos norte-americanos Barney Glaser e Anselm Strauss na década de 1960 como uma alternativa para que o desenvolvimento de pesquisas qualitativas não se baseasse somente na análise e dedução de hipóteses, a partir de teorias já existentes. A sua utilização é indicada, principalmente, quando o tópico de interesse ainda não foi previamente estudado ou é escassa a produção científica sobre o mesmo. No contexto da pesquisa em enfermagem e saúde, a TFD tem se mostrado bastante útil para compreender as ações de indivíduos e/ou grupos sociais diante de situações vivenciadas em um determinado contexto. ${ }^{1-3}$

Desde a sua criação, a TFD tem passado por muitos desdobramentos, principalmente porque os idealizadores adotaram linhas de trabalho diferentes. ${ }^{1,3}$ Nesse sentido, o objetivo deste texto é apresentar três novas possibilidades de aplicação da TFD: modelo paradigmático com três componentes, análise situacional de Adele Clarke e análise dimensional de Leonard Schatzman, as quais ainda são pouco difundidas na pesquisa em enfermagem no Brasil.

O modelo paradigmático com três componentes é uma inovação da perspectiva straussiana da TFD, cujos representantes são Anselm Strauss e Juliet Corbin. A principal característica dessa perspectiva é a utilização de um modelo paradigmático para auxiliar no estabelecimento de relações entre as categorias e na identificação do fenômeno ou categoria central da pesquisa. Tradicionalmente o modelo paradigmático era composto por cinco componentes: contexto, condições causais, condições intervenientes, estratégias e conseqüências. $^{2}$ No entanto, na nova atualização da principal obra dessa perspectiva, os autores preconizam três componentes: condições, ações-interações e conseqüência. ${ }^{4}$ Essa

\footnotetext{
1 Enfermeiro. Doutor em Enfermagem. Professor Adjunto da Universidade Federal de Santa Catarina, Florianópolis, SC, Brasil. E-mail: jose.santos@ufsc.br
} 


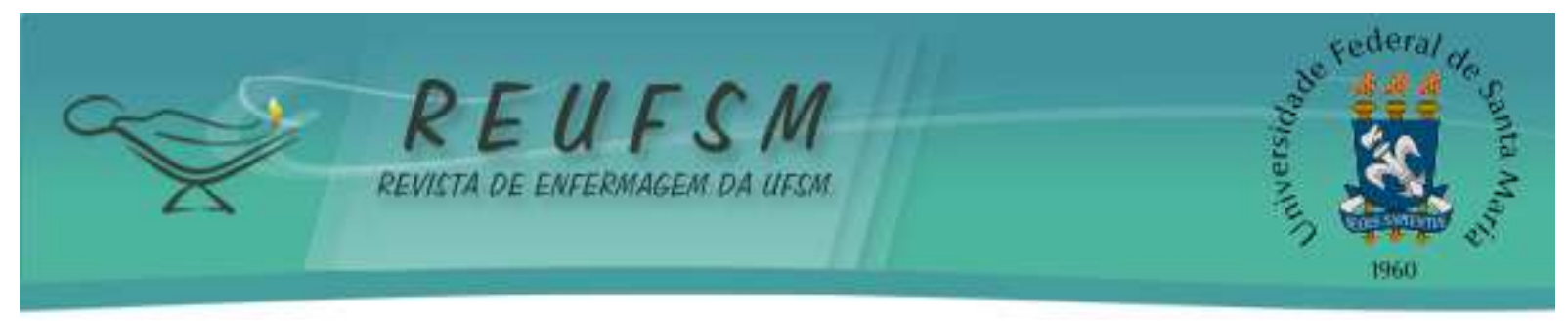

mudança possibilita maior flexibilidade aos pesquisadores no desenvolvimento da teoria e pode ser associada à influência do construtivismo no desenvolvimento da pesquisa qualitativa.

A análise situacional de Adele Clarke é a derivação pós-moderna da TFD. Nessa vertente, existe apenas a codificação aberta e o paradigma de codificação é substituído por matrizes situacionais, que geram mapas situacionais. Os principais tipos de mapas são: mapas situacionais, mapas de arena/mundos sociais e mapas posicionais. Outra diferença dessa abordagem da TFD é a substituição do conceito de "processo social básico" pelo conceito de "mundos/arenas/negociações sociais" com o intuito de deslocar o foco da ação para a compreensão sistêmica dos fluxos de poder inerentes a uma situação de análise. Essa vertente tem sido usada, principalmente, em estudos sobre gênero e sexualidade e com associação ao referencial de Michel Foucault. ${ }^{3,5}$

A análise dimensional surgiu a partir dos estudos de Leonard Schatzman, em parceria com Anselm Strauss. A principal motivação para o seu desenvolvimento foi a dificuldade de gerar categorias unicamente a partir dos dados, conforme proposto na versão original da TFD. Assim, a proposta da análise dimensional é a identificação prévia pelo pesquisador de dimensões características do seu campo de estudo para auxiliar no estabelecimento de comparações e relações entre os dados e o contexto do fenômeno em investigação. Ao longo da pesquisa, algumas dimensões previstas inicialmente podem ser eliminadas, assim como outras podem ser acrescentadas. Ao final, a teoria surge da comparação entre o contexto e as dimensões que se mostram mais importantes no estudo. ${ }^{3,6}$

Como o uso dessas vertentes da TFD na pesquisa em enfermagem ainda é incipiente no Brasil, elas podem ser consideradas novas possibilidades para pesquisadores interessados na utilização do método. Além disso, a adoção de uma dessas perspectivas representa uma oportunidade para contribuir com o desenvolvimento e ampliação do uso da TFD no contexto brasileiro. Antes de finalizar, é importante mencionar que as vertentes glaseriana e construtivista da TFD são igualmente importantes para a construção de novos conhecimentos na Enfermagem. No entanto, não foram abordadas aqui por já serem mais conhecidas no meio acadêmico e científico. Portanto, reforça-se o potencial e as múltiplas possibilidades de aplicação da TFD para a pesquisa em enfermagem. 


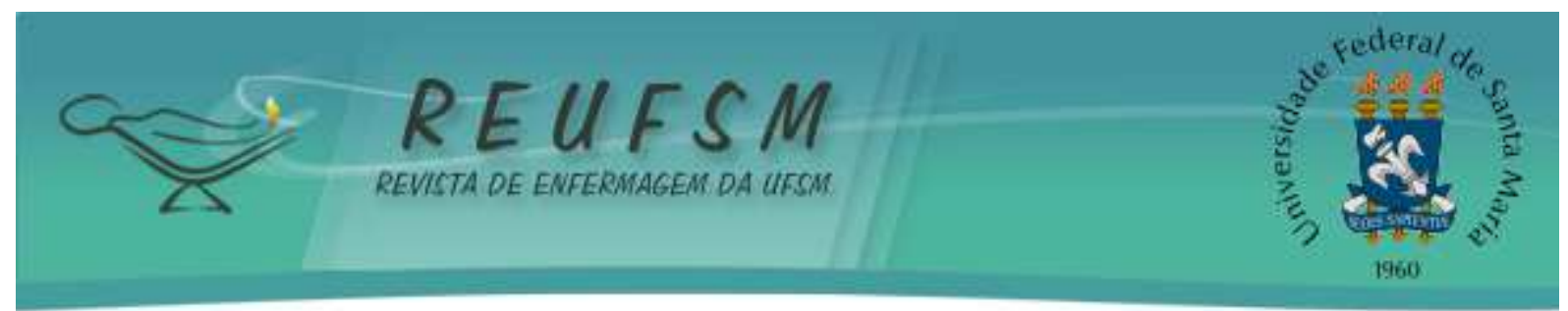

\section{REFERÊNCIAS}

1. Santos JLG, Erdmann AL, Sousa FGM, Lanzoni GMM, Melo ALSF, Leite JL. Perspectivas metodológicas para o uso da teoria fundamentada nos dados na pesquisa em enfermagem e saúde. Esc Anna Nery [Internet]. 2016 [acesso em 2017 mar 10];20(3):e20160056. Disponível em: http://www.scielo.br/scielo.php?script=sci_arttext\&pid=S1414-81452016000300201\&lng=en.

2. Leite JL, Lima SBS, Soares RSA, Eberhardt TD. Teoria Fundamentada nos Dados: possibilidade para a pesquisa qualitativa em enfermagem. Rev Enferm UFSM. 2016 jul/set;6(3).

3. Camalhão MI, Camalhão S. Grounded Theory: adaptações ao contexto da deficiência e educação. Indagatio Didactica, 2014;6(3):140-55.

4. Corbin J, Strauss A. Basics of qualitative research: techniques and procedures for developing Grounded Theory. California: SAGE; 2015.

5. Clarke AE. Situational analysis. Grounded Theory after the postmodern turn. Thousand Oaks, USA: SAGE Publications; 2005.

6. Schatzmann L, Strauss A. Field research: strategies for natural sociology. Toronto: Prentice-Hall ink; 1973. 